九州大学学術情報リポジトリ

Kyushu University Institutional Repository

\title{
Genotype by environment interactions (GEIs) for barley grain yield under salt stress condition
}

\section{Elakhdar, Ammar}

Field Crop Research Institute, Agricultural Research Center, Egypt I Institute of Plant Genetic Resources, Kyushu University

Kumamaru, Toshihiro

Institute of Plant Genetic Resources, Kyushu University

Smith, Kevin P.

Agronomy and Plant Genetics, University of Minnesota Saint Paul

Brueggeman, Robert S.

Department of Plant Pathology, North Dakota State University

他

http://hdl. handle. net/2324/1868363

出版情報: Journal of Crop Science and Biotechnology. 20 (3), pp.193-204, 2017-09-27. Springer バージョン：

権利関係: (C) Korean Society of Crop Science and Springer 2017 
Click here to view linked References
1
2
3
Short Title
Genotype by environment interactions

\title{
Full Title \\ Genotype by environment interactions (GEIs) for barley grain yield under salt stress condition
}

\author{
Authors: \\ Ammar Elakhdar', ${ }^{1,}$ \\ Toshihiro Kumamaru², \\ Kevin P. Smith ${ }^{3}$, \\ Robert s. Brueggeman ${ }^{4}$, \\ Ludovic J.A. Capo-chichi ${ }^{5}$, \\ Shyam Solanki ${ }^{4}$
}

*Corresponding author: a.elakhdar@kyudai.jp

Keywords: Hordeum vulgare, G $\times$ E interaction, AMMI, Tai's stability parameters, salt stress

\section{Approval}

We authors and our institutions have read and are fully aware of the journal policy. 


\section{Genotype by environment interactions (GEIs) for barley grain yield under salt stress condition}

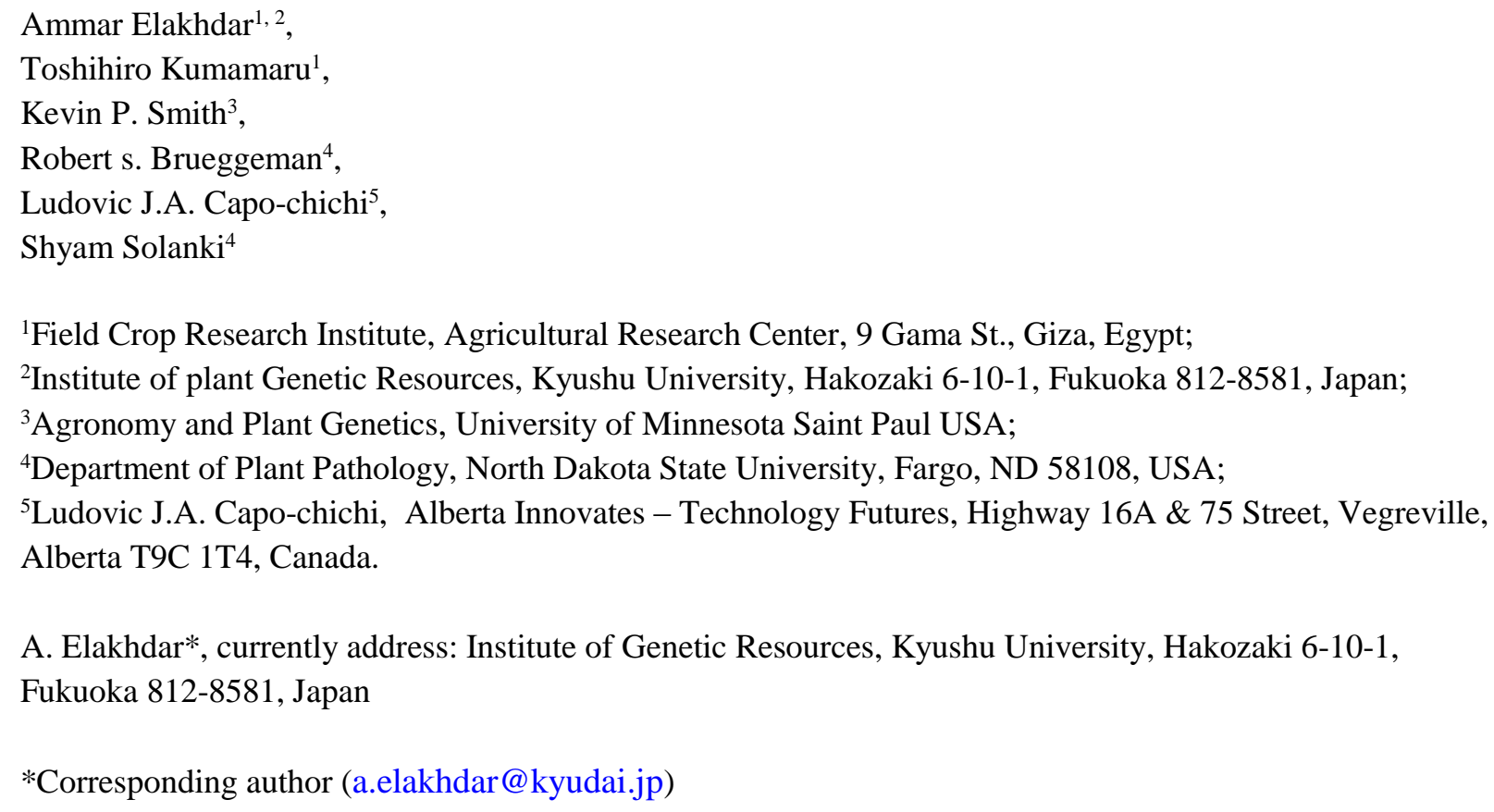

19 Abstract

20 Changes in the relative genetic performance of genotypes across environments are referred to as 21 genotype $\times$ environment interactions (GEIs). GEIs can affect barley breeding improvement for 22 salt-tolerance because it often complicates the evaluation and selection of superior genotypes 23 properly. The present study was seeking to evaluate the GEIs over 60 barley genotypes that were 24 evaluated for yield components and grain-yield in six-salinity environments in North Delta, 25 Egypt. Data were analyzed using the additive main effects and multiplicative interaction 26 (AMMI) and Tai's stability parameters. GEIs effects on yield explained 20.3, 20.1, 14.6 and $2733.0 \%$ of the total variation besides, the first two principal components account for $67.3,56.3$, 2864.3 and $83.7 \%$ of the explained variance in the four sets, respectively. The ideal genotype29 model are G-4, G-7, G-20, G-34, G-36, and G-39 which, were most stable and high-yield 30 genotypes across environments $\left(\mathrm{GY}>2.00 \mathrm{t} \mathrm{ha}^{-1}\right)$, and located almost zero and/or close to zero 
1 projection onto the AEC ordinate. Tai's stability parameters demonstrated that they were more

2 responsive to the environmental changes. The genotypes G-50 and G-53 showed perfect/static

3 stability ( $\alpha=-0.95,-0.91$, respectively). In contrast, the genotype; G-36 had $\alpha=0$ and $\lambda=1.10$,

4 indicating parallel with the environmental effects followed by G-44. Overall, we found that GEIs

5 for grain yield is a highly significant in all sets, suggesting that responded differently across

6 environments. This interaction may be a result of changes in genotypes' relative performance

7 across environments, due to their differential responses to various abiotic factors.

8 Keywords: Hordeum vulgare, $\mathrm{G} \times \mathrm{E}$ interaction, AMMI, Tai's stability parameters, salt stress

\section{Introduction}

10 Climate changes affect agricultural productivity globally and may outcome in strong 11 influence on agriculture, particularly on crop yield improvement. Crops are largely certain by 12 climatic situation during growing season, thus even slight deviations from optimal conditions can 13 seriously overhang yield (Lobell et al. 2011; Kole et al. 2015). Therefore, understanding of the 14 environmental factors effect on crop production could reduce the possibilities of significant yield 15 losses and improve the selection of elites cultivars for using in the target aspects and area (Smith 16 and Tirpak 1989). Soil salinity is one of the most important abiotic stresses worldwide, affecting 17 crops production and act as a major obstacle to increasing barley production in growing areas 18 worldwide, particularly in the Mediterranean region (Rodriguez et al. 2008; Sayar et al. 2010; 19 Rharrabti et al. 2013; Elakhdar et al. 2016a). Globally, it is estimated that $19.5 \%$ of irrigated 20 land (about 230 million ha) and almost $2.1 \%$ of dry land agriculture (about 45 million ha) is 21 affected by salinity (FAO 2015).

22 Today cultivated barley became the fourth most abundant cereal in term of area and 23 harvested tonnages as well (FAO 2015). Barley is widely adapted to various environmental 
1 conditions and is more stress tolerant compared with its close relative wheat (Lobell et al. 2011)

2 Barley production in Egypt is affected by increasing dryland salinity, which severely limits

3 growth and reduces yields (Elakhdar et al. 2016a). To maintain high agricultural productivity, the

4 development of cultivars with high-yield potential is the ultimate goal of plant breeders in a crop

5 improvement program. Recently, the barley breeding program in Egypt has placed special focus

6 on developing barley cultivars with improved grain yield under different stress conditions, and

7 resistance to major barley diseases. In addition to high-yield potential, a new cultivar should

8 have stable performance and broad adaptation over a wide range of environments.

9 In many aspects of plant breeding, studying of genotype-by-environment interaction (GEI)

10 plays an important role for identifying high-yield and stable genotypes. It continues to be a 11 challenging issue among plant breeders and agronomists when conducting crop performance 12 trials across diverse and unpredictable environments (Ceccarelli 1996; Rodriguez et al. 2008; 13 Hongyu et al. 2014). Indeed, most of the economic or quantitative traits are controlled by 14 complex gene networks, which are in turn affected by the environment (Cooper 1996; 15 Haussmann et al. 2004). For this reason, understanding the causes of GEI would help in 16 developing and breeding genotypes, which show satisfactory performance in several 17 environments and adapting as well. The additive main effects and multiplicative interaction 18 (AMMI) model are a combined analysis that incorporates both multiplicative components and 19 the additive of the two-way data structure that clearly distinguishes between the main and 20 interaction effects (Shafii and Price 1998; Hongyu et al. 2014). Therefore, it is essential to 21 assess the genotypes sensitivity during the environmental in terms of simultaneous stable and 22 higher yields genotypes ( Yan et al. 2007; Balestre et al. 2009). 
For the past decades, the concept of GEI and its stability statistics were being analyzed in

2 different ways. In stability studies, the interaction term is separated into two components; the

3 linear response to environmental effects, which is measured by a statistic $(\alpha)$, and the deviation

4 from the linear response, which is measured by another statistic $(\lambda)$, that reported by (Tai 1971).

5 A perfectly stable variety has $(\alpha, \lambda)=(-1,1)$ and a variety with average stability is expected to

6 have $(\alpha, \lambda)=(0,1)$. Tai's analysis also supports a method of obtaining the prediction interval for

$7 \quad \alpha=0$ and a confidence interval for $\lambda$ values, so that the genotypes can be distributed graphically

8 in different stability regions of the Tai's plot.

9 Thus, this paper aims to apply AMMI biplot and Tai's stability statistical models for 10 determination of the magnitude and pattern of genotype $\times$ environment interaction GEI effects 11 and performance stability of grain yield under the salt-affected soil on a set of Egyptian spring 12 barley genotypes.

13 Materials and methods

14 Germplasm

15 The plant material consisted of a set of 60 hulled and hull-less barley genotypes (53 16 advanced lines and seven cultivars) presented in (supplemental Table 1). The genotypes were 17 developed includes progeny selection on ear-to-row method (modified pedigree method) at Field 18 Crops Research Institute (FCRI), Agricultural Research Center (ARC), Egypt.

\section{Total protein profiling using SDS-PAGE}

20 To study the genetic variation among the genotypes using SDS-PAGE; seed coats were 21 removed and homogenized using $8 \mathrm{M}$ urea buffer (seed per genotypes). After vigorous vortex, 22 samples were subjected to centrifugation at $12,000 \mathrm{rpm}$ for $10 \mathrm{~min}$ at $4{ }^{\circ} \mathrm{C}$ and clear supernatants 23 were used for analysis. Protein profiling of samples was performed using SDS-PAGE as 
1 described by (Laemmli 1970). Equal volumes of proteins supernatants $(8 \mu \mathrm{l})$ from each sample

2 were loaded into $14 \%$ gel. Staining of gels was done in $0.025 \%$ Coomassie Brilliant Blue 250

3 containing $40 \%$ methanol and $7 \%$ acetic acid.

4 Experimental layout; design and testing locations

5 The genotypes were planted into four-sets, consisted 15 genotypes each (the large layouts are

6 not recommended instead of the variation caused by the salinity). The treatments were laid out in

7 a randomized complete block design (RCBD) with three replications. The genotypes were

8 evaluated in three salt-affected soil locations during two cropping season; 2012-2013 and 2013-

9 2014. Each year and location were treated as a separate environment, making six-test 10 environments $[(\mathrm{E} 1$ to $\mathrm{E} 6)(\mathrm{E}=$ year $\times$ location combination $)]$, the weather and climate 11 information for the locations were described in (Table 1). Each plot was four rows, 2-m long 12 with 30-cm apart. Data were recorded from the central rows on 15-yield traits as the following; 13 Days to Heading (DH) and Maturity (DM), Flag Leaf Area $\mathrm{cm}^{2}$ (LA), Chlorophyll content (Chl 14 as SPAD value), Plant Height (PH), Spike Length (SL), Peduncle length (Ped), Number of 15 Tillers/ $\mathrm{m}^{2}$ (NT), Number of Grains/ spike (NG), 1000-Grain weight (GW), Grain Yield GY $16 t h a^{-1}$, Biological Yield BY $t h a^{-1}$, Grain Filling Period (GFP), Grain Filling Rate (GFR) and 17 Harvest Index (HI), However our study focus only on the grain yield in details. Grain yield was 18 measured from a net plot size of $1 \mathrm{~m}^{2}$ and was converted into $\mathrm{t} \mathrm{ha}{ }^{-1}$. At harvest, soil samples 19 were taken from upper soil layer $(0-30 \mathrm{~cm})$ to conduct chemical and physical analysis (Table. 2$)$. 20 Data Analysis

21 The analysis of variance ANOVA for the grain yield values was performed using the general 22 linear model (GLM) procedure to partition the total variation into components due to genotype 23 (G), environment (E) and GEIs effects. As suggested elsewhere (Kang and Gauch 1996), the 
1 appropriate linear model for the genotypic value of genotype $i$ grew in the environment (year $x$

2 location) $\mathrm{j}$ and replication $\mathrm{r}$ within this $\mathrm{j}$ environment was determined by:

$3 \quad \mathrm{~g}_{\mathrm{ijl}}=\mu+\mathrm{E}_{\mathrm{j}}+r / E_{j l}+\mathrm{G}_{\mathrm{i}}+\mathrm{GE}_{\mathrm{ij}}+\mathrm{e}_{\mathrm{ijl}}$.

4 Where $\mu$ is the general mean, $\mathrm{E}_{\mathrm{j}}, r / E_{j l}$ and $G_{i}$ are the main effect of respective environment,

5 replication within environment and genotype, whereas $G E_{i j}$ and $e_{i j l}$ are the GEIs and the

6 experimental error. Genotype and environment were considered as a fixed and random effect,

7 respectively.

\section{The AMMI model}

9 Multivariate stability measures additive main effects and multiplicative interaction (AMMI) 10 equation by (Gauch 1992) is;

$11 Y_{g e r}-\alpha-\beta e+\mu=\Sigma_{n} \lambda_{n} \gamma_{g n} b_{e n}+\rho_{\text {ge }}+\varepsilon_{\text {ger }}$

12 Where $Y_{g e r}$ is the plot of genotype $\mathrm{g}$ in the environment e and replicate $\mathrm{r} ; \mu$ is the grand mean; $\alpha$ 13 is the deviation of the genotype $\mathrm{g}$ from the grand mean; $\beta \mathrm{e}$ is the deviation of the environment $\mathrm{e}$ 14 from the grand mean; $\lambda_{n}$ is the singular value of PCA axis n; $\gamma_{g n}$ is the genotype eigenvector for 15 axis $b_{e n}$ is the environment eigenvector; $\rho_{\mathrm{ge}}$ is the residual of the GEI and $\varepsilon$ ger is the error term.

16 The basic model for a GGE bi-plot equation by (Yan et al. 2007) is;

$17 \hat{Y}_{i j}-\beta e=\lambda_{1} \varepsilon_{i 1} \eta_{1 j}+\lambda_{2} \varepsilon_{i 2} \eta_{2 j}+\varepsilon_{i j}=g_{i 1} e_{1 j}+g_{i 2} e_{2 j}+\varepsilon_{i j}$. Where $\hat{Y}_{i j}$ is the expected 18 yield of genotype $\mathrm{i}$ in environment $\mathrm{j}$ is the grand mean of all observations and $\beta e$ is the main 19 effect of environment j. $\lambda_{1}$ and $\lambda_{2}$ are the singular values of first and second largest PC1 and $20 \mathrm{PC} 2$, respectively; $\varepsilon_{i 1}$ and $\varepsilon_{i 2}$ are the eigenvectors of genotype i for PC1 and PC2, respectively; $21 g_{i 1}$ and $e_{1 j}$ are called the primary scores for genotype i and environment $\mathrm{j}$, respectively; $g_{i 2}$ and 
$1 e_{2 j}$, the secondary scores for genotype $\mathrm{i}$ and environment $\mathrm{j}$, respectively; and $\varepsilon_{i j}$ is the residue

2 not explained by the primary and secondary effect. $g_{i l}=\lambda_{l}^{f i} \varepsilon_{i j}$ and $e_{l i}=\lambda_{l}^{1-f i} \eta_{1 j}$. Where $f$

3 is the partition factor and theoretically it can take any value between 0 and 1 .

$4 \quad$ AMMI analysis and AMMI2 GE bi-plot was completed using the standard procedures and 5 analyzed through GeneStat software (GenStat 2011). AMMI1 graph, histogram, and box-plot

6 were performed using the scatter plot Quantum XL analysis runs in Excel spreadsheet.

$7 \quad$ Tai's model

9 variance component for a pairwise GEI. The linear response to environmental effects was 10 calculated by $\alpha_{i}$ statistic and the deviation from the linear response was calculated by $\lambda_{i}$ statistic.

11 A perfectly stable genotype has $\left(\alpha_{i}, \lambda_{i}\right)=(-1,1)$ and the genotype with average stability has $12\left(\alpha_{i}, \lambda_{i}\right)=(0,1)$ and the value $(\alpha<0, \lambda=1)$ refers to the above average stability.

\section{Results}

\section{Genotype mean performance}

15 The mean grain yield performance varied from $4 \mathrm{t} \mathrm{ha}^{-1}$ for $\mathrm{G}-43$ to $0.63 \mathrm{t} \mathrm{ha}^{-1}$ for G-44 and 16 G-59 across the all diversified salt-environments, indicating large variation in yield potential of 17 genotypes (Table 3). The highest mean yield for an individual genotype per set in an individual 18 environment were $\left(3.13,3.02,3.33 \mathrm{t} \mathrm{ha}^{-1}\right.$ for G-8 in E4, E5, and E6)/ set-1, (3.33 $\mathrm{t} \mathrm{ha}^{-1}$ for G-18 19 in E3, E5, and E6)/ set-2, (3.33 and $3.34 \mathrm{t} \mathrm{ha}^{-1}$ for G-32 in E3 and E5)/ set-3 and (2.81 $\mathrm{tha}^{-1} \mathrm{for}$ 20 G-46 in E3 and E6)/ set-4, respectively.

21 In addition, the genotypes combined means obtained from the evaluation of barley genotypes for 22 yield stability over environments are summarized in (Table 4). The grain yield ranged from a 23 high of $2.52,2.51,2.37$, and 2.00 to a low of $1.79,1.76,1.58$, and $1.17 \mathrm{t} \mathrm{ha}^{-1}$ in set $1,2,3$, and 4 , 
1 respectively. The highest genotypes grain yield performance was recorded for G-8, G-22, G-3,

2 and G-23 as hulls-type; moreover, other high yielding genotypes were G-32 and G-33 as naked-

3 type over the environments.

4 The molecular analysis among the genotypes was matched with SDS-PAGE patterns seed

5 storage protein (Fig. 1). The seed protein profiles of 60 barley accessions showed diversity in the

6 banding pattern. The types of band pattern were depicted on the basis of their molecular weight.

7 The different sizes of the protein banding patterns of all the genotypes studied are represented in

8 the schematic drawing (Fig. 1 a) (only, some of the 60 genotypes were present). Using the

9 hordein bands pattern, the genetic distance was presented as UPGMA (based on Nei's genetic

10 distance) dendrogram showing the relationship between various genotypes (Fig. 1 b).

\section{Environment effects and classification}

12 Based on the grain yield data the environments were classified into two groups (Fig. 2) 13 according to Ward cluster analysis. In the cluster analysis, two environments (E5 and E2), are 14 corresponding to the salt stress with high and medium yield potential, respectively (Table 3 ).

15 The low-yielding environment per sets were $1.28 \mathrm{t} \mathrm{ha}^{-1}$ E2/ set-1, $1.44 \mathrm{t} \mathrm{ha}^{-1}$ E2/ set-2, $1.55 \mathrm{t}$ $16 \mathrm{ha}^{-1} \mathrm{E} 4 /$ set-3, and, $1.52 \mathrm{t} \mathrm{ha}^{-1} \mathrm{E} 1 /$ set-2 (Table 5).

17 Genotype - By - Environment interaction

18 The analysis of variance for grain yield of each genotype group in each environment based 19 on GE interaction effects is presented in (Table 6). The treatments, locations, genotypes, and the 20 interaction effects GEIs were highly significant $(\mathrm{P} \leq 0.001)$ of the total variance. The location 21 (E) effect for the first three-sets was much stronger than the GEI effect, which explains $33.34 \%$, $2222.16 \%$ and $49.92 \%$ (ranged from 3.59 to 5.31-fold the genotype effect) of the variance 23 component (VC \%), respectively. While the interaction variance component (VC \%) in the set-4 
1 recorded $33.00 \%$ in contrast, $11.50 \%$ for the location (E). At the same time, the genotype effect

2 was slightly higher than the location for the set-4 (Table 6).

\section{Additive Main Effects and Multiplicative Interaction}

4 The stability of the genotypes was achieved by drawing an average environment coordinate (AEC) on

5 the genotype- focused bi-plot. Based on IPCA scores, some genotypes such as G-6, G-9, G-21, G-

642 , G-50, and G-58 had relatively high positive interaction with the environment. On the other

7 hand, the genotypes coded G-1, G-5, G-18, G-20, G-35, G-46, and G-59 had high negative

8 interaction with the environment (Table 4). These genotypes were, therefore, among the most

9 responsive genotypes to environments, in contrast, the genotypes; G-4, G-7, G-12, G-20, G-22, 10 G-23, G-31, G-34, G-36, G-39, and G-54 were the most stable genotypes, as it was located 11 almost zero and/or close to zero projection onto the AEC ordinate, expressed general adaptation. 12 From these stable genotypes, six-genotypes coded; G-4, G-7, G-20, G-34, G-36, and G-39 were 13 high-yielding performance $\left(>2.00 \mathrm{t} \mathrm{ha}^{-1}\right)$ compared with the others. This observation means that 14 these genotypes most stable with respect to performance across environments. The environments 15 that mostly contributed to the total GEI according to on IPCA scores were E5/ set-1, E1/ set-3, $16 \mathrm{E} 4 /$ set-3 and E5/ set-4, that mean the differences across all of the environments were mainly 17 summarized by the IPCA1 (Table 5).

18 Genotype (G), environment (E) and genotype-by-environment (GE) interactions were 19 measured by the AMMI model (Table 6). The first two principal component axes of the 20 interaction PCA explain most of the GEI effect: $44.60 \%, 32.83 \%, 42.14 \%$ and $46.91 \%$ captured 21 by the PCA1; 22.69, 23.42, 22.18 and $36.78 \%$ by the PCA2, in the four sets, respectively. AMMI 22 analysis of variance indicated that two PCA were high significant $(\mathrm{P}<0.01)$ in the four sets. The 23 AMMI bi-plot analysis for barley grain yield grown in six environments is presented in (Fig. 3). 24 The $x$-axis shows the main effects, while the $y$-axis shows the first PCA axis. Partitioning of GEI 
1 by the GGE bi-plot showed that PCA accounted for $67.28,56.25,64.32$ and $83.69 \%$ of the total

2 variation in the grain yield for the four sets, respectively. The environments that mostly

3 contributed to the total GEI were E6 and E4 for the $1^{\text {st }}$ set; E1 and E3 for the $2^{\text {nd }}$ set; E2 and E5

4 for the $3^{\text {rd }}$ set; and E6 and E5 for the $4^{\text {th }}$ set. Therefore, most results could be graphically

5 presented in an AMMI1 bi-plot (Fig. 3). It was found that the variation of the environment was

6 higher than that of genotype.

\section{$7 \quad$ Tai Stability analysis}

8 Tai stability model partitions the GEIs consequence into two parameters: $\alpha$, that calculates

9 the linear response to environmental effects and $\lambda$ that calculates the deviation from the linear 10 response in terms of the magnitude of the error variance.

11 Based on these parameters, a perfectly stable-genotype is one with a deviation from the linear 12 response of +1 and an environmental effect of -1 , so that $(\alpha, \lambda)=(-1,1)$. In this investigation 13 distribution of 60 barley genotypes were appeared different stability regions based on Alpha14 Lambda parameters (Fig. 4). The $\lambda$ values for G-1, G-3, G-6, G-8, G-16, G-17, G-18, G-21, G-46, 15 G-58, and G-59 were significantly different from unity, but none of them showed an $\alpha$ value of 161 except for G-50 and G-53 = -97. Although, the genotypes G-50 and G-53 showed perfect/static 17 stability ( $\alpha=-0.95,-0.91$, respectively), but they recorded a medium (1.76, and $\left.1.17 \mathrm{t} \mathrm{ha}^{-1}\right)$ grain 18 yield values in set-4, respectively. Alternatively, Tai's statistics parameters for G-36 showed $\alpha=$ 190 and $\lambda=1.10$, this result indicated that G-36 of the tested genotypes average stability followed 20 by G-44. The distribution of $\alpha$ and statistic for genotypes G-7, G-19, G-25, G-31, G-37, and G2160 were negative $(\alpha>0, \lambda=1)$ referring that those genotypes were responsive in relatively to the 22 poor environment and below average stability (Table. 4). Significant effects were found in all 23 environments for grain yield, and present in the box plot (Fig. 5). In the simplest box plot, the 
1 central rectangle spans the first quartile to the third quartile. Simple Pearson's correlation

2 coefficients were computed between 15-physiological and morphological traits, under salinity

3 condition, positive correlations between the GY and MD $(r=0.36, \mathrm{P}<0 \cdot 01), \mathrm{NT}(\mathrm{r}=0.51, \mathrm{P}<$

$4 \quad 0 \cdot 01)$ and BY $(r=0.64, \mathrm{P}<0.01)$ were observed (Table 7). Moreover, negative correlations

5 between the Chl (SPAD value) and GY ( $\mathrm{r}=-0.27, \mathrm{P}<0 \cdot 01)$. Analyses of histogram's (Fig. 6)

6 showed that salinity had a significant effect on grain yield at all sets across the six environments.

7 Discussion

9 advantage from comprehension the impacts of changes on the crops production to date. In this 10 study, the variance components explained that both location (E) and genotypes $\times$ environments $11(\mathrm{G} \times \mathrm{E})$ components were very important (Table 6). For the grain yield, location effects were 12 high significant for all sets $(\mathrm{P} \leq 0.001)$ and ranged from 3.59 to 5.31-fold the genotype effect, 13 suggesting that barley breeders can either develop specific-genotypes for each environment 14 and/or with selecting genotypes that usually perform to a wide range of environments (Rodriguez 15 et al. 2008).

16 In this study, AMMI model had been exploited in the variety evaluation of barley (Rodriguez 17 et al. 2008; Yahiaoui et al. 2014), durum wheat (Reza et al. 2015), rice (Liu et al. 2002), faba 18 bean (Temesgen et al. 2015) and maize (Demissew et al. 2016). The interpretation of the GEIs 19 was established on linear regression (Finlay and Wilkinson 1963). A high positive interaction 20 with the environments appeared from some genotypes such as G-6, G-9, G-21, G-42, G-50 and 21 G-58. On contrary, the genotypes coded G-1, G-5, G-18, G-20, G-35, G-46, and G-59 had high 22 negative interaction with the environment (Table 4). The GEIs are important factors in any crop 23 variation, for example, the performance of protein quality in maize may be affected by tropical- 
1 highland temperature in Ethiopia (Demissew et al. 2016), the variation in barley agronomic and

2 quality characteristics (Nurminiemi et al. 2002) and the effect on barley grain yield (Dehghani et

3 al. 2006).

4 The main effects ( $\mathrm{G}$ and $\mathrm{E})$ represents in abscissa and it's the PC1 scores ordinate (Zobel et

5 al. 1988). Our results showed that six genotypes coded; G-4, G-7, G-20, G-34, G-36, and G-39

6 were high-yielding performance (> $2.00 \mathrm{t} \mathrm{ha}^{-1}$ ) and located almost zero and/or close to zero

7 projection onto the AEC ordinate. This observation means that these genotypes most stable with

8 respect to performance across environments. Therefore, AMMI1 bi-plot provides a means of

9 imagination the mean performance of $\mathrm{G}$ and the stability PC1 of the genotypes, simultaneously

10 (Gauch and Zobel 1997; Yan and Kang 2003; Yan et al. 2007). GGE bi-plot showed the most

11 environments contributed to the total GEIs which were E4, E3, E5, and E6 in the four sets,

12 respectively (Fig. 3). The GGE bi-plot has therefore been used in crop variety trials to effectively

13 identify the best-performing genotype(s) across environments, whereby specific genotypes can

14 be recommended to specific mega-environments and evaluate the yield and stability of genotypes

15 (Rharrabti et al. 2003; Yan and Kang 2003; Gauch 2006 and Rodriguez et al. 2008).

16 The combined analysis of variance is a sign of the environments (Table 6). This provided a

17 large difference among environmental means in significant yield variations. Moreover, the 18 environments contributed a large effect on yield stability. This might probably be due to 19 differences in the characteristics of salt-affected soils, which differ, not only in their chemical, 20 physical and biological properties as shown in (Table 2) and described previously by Elakhdar et 21 al. (2016b), but also in their geographical distribution (semi-arid and Mediterranean climate) 22 (Table 1). As the location was significant for the grain yield, the ideal genotype-model should 
1 have high mean and yield stability further, the breeders should develop stable genotypes that

2 perform well over environments (Yan and Kang 2003; Gauch 2006).

3 On the other hand, the diversity in the grain yield was observed a high significantly 4 associated with MD, NT, and BY (Table 7) across the environments. This funding probably,

5 because of the nature of the salt-soil composition, so that; causes of the growth unstable under

6 saline conditions (Munns 1993; Munns and Teste 2008). Several studies have reported the

7 contribution of the environment affecting yield stability (Yan et al. 2007; Gauch et al. 2008;

8 Balestre et al. 2009; Yang et al. 2009; Malosetti et al. 2013). Garcı'a del Moral et al. (2002)

9 reported that cereals have shown how environmental differences in yield can be affected by 10 variations in spike number and fertility.

\section{Tai's stability model}

12 Tai's figure areas I, II and III indicate regions of average, above and below average 13 stability, respectively. The genotypes G-5, G-9, G-40, G-41, G-47, G-53 and G-55 showed $\lambda$ 14 values, significantly different from unity; moreover, the distribution of the 60 genotypes on $\alpha-\lambda$ 15 space showing different stability regions was indicated in (Fig. 4). It should be noted that the 16 larger the $\lambda$ value, the more difficult it is to show a significant difference between the $\alpha$ estimate 17 and $\alpha=0$ and hence the $\alpha$ statistic becomes less meaningful in interpreting the linear response of 18 a cultivar over varying environments (Tai 1971; Thillainathan et al. 2001).

\section{Conclusions}

20 This finding indicated that using AMMI and Tai's analysis would favor the simultaneous 21 development of stable and high yielding barley genotypes across salt location. AMMI analysis 22 appeared to be able to extract a large part of the interaction and is thus more efficient in 23 analyzing $\mathrm{G} \times \mathrm{E}$ interaction pattern. The genotypes; G-4, G-7, G-20, G-34, G-36, and G-39 were 
1 the most stable genotypes with high-yield $\left(\mathrm{GY}>2.00 \mathrm{t} \mathrm{ha}^{-1}\right)$ across environments. Tai's analysis

2 provides a method of obtaining the prediction interval for $\alpha=0$ and a confidence interval for $\lambda$

3 values so that genotypes can be distributed graphically in different stability regions. Two

4 genotypes G-50 and G-53 showed perfect/static stability ( $\alpha=-0.95,-0.91$, respectively). In

5 contrast, the genotype; G-36 had $\alpha=0$ and $\lambda=1.10$, indicating parallel with the environmental

6 effects followed by G-44.

7 A very strong GEI for grain yield is observed, suggesting that may be a result of changes in

8 genotypes' relative performance across environments, due to their differential responses to

9 various abiotic factors which are sited in a typical Mediterranean area. However, both mean yield 10 and stability should be considered simultaneously to exploit the useful effects of $\mathrm{G} \times \mathrm{E}$ 11 interaction and to make the selection of favorable barley genotypes more precise.

12 Acknowledgment

13 We thank Prof. Maher Noaman, Field Crops Research Institute, ARC for critical reading, 14 editing of the manuscript and valuable comments. 


\section{Table's Legends}

2 Table 1. Description of the testing location during the two seasons

3 Table 2. The soil properties; chemical, physical, and textural characterize for the testing location.

4 Table 3. The performance of grain yield $\left(\mathrm{tha}^{-1}\right)$ for 60 barley genotypes tested in six 5 environments.

6 Table 4. AMMI adjusted mean grain yield $\left(\mathrm{t} \mathrm{ha}^{-1}\right)$, IPCA scores, and Tai's stability parameters of 7 genotypes of 60 spring barley evaluated across six-environments in Egypt.

8 Table 5. The environments mean grain yield ( $\left.\mathrm{t} \mathrm{ha}^{-1}\right)$, and IPCA scores of 60 spring barley

9 evaluated across six-environments in Egypt.

10 Table 6. Analysis of variance for grain yield of 60 barley genotypes tested across six salt- affected 11 soil environments.

12 Table 7. Pearson correlation matrix for salt-related traits across six environments. 


\section{$1 \quad$ Figures Legends}

2 Fig.1. The SDS-PAGE fractionated proteins showed distinction in the number and molecular

3 weight of these polypeptides. The major components of all genotypes were in the hordein

4 fractionation and the arrow track indicates D-hordein $>100 \mathrm{kDa}$ and the brackets indicate, C-

5 hordeins $55-75 \mathrm{kDa}$ and 35-46 $\mathrm{kDa}$ B-hordeins (a), A dendrogram showing the relationship of

6 the genotypes based on protein (hordein) bands (b) Nei (1978).

7 Fig.2. Ward's dendrogram presenting the classification of 6-testing environments based on

8 environment mean yield. E, year-location combinations during 2012-14: E1: Elhossinia

9 2012/2013; E2: Seirw 2012/2013; E3: Sakha 2012/2013; E4: Elhossinia 2013/2014; E5: Seirw

10 2013/2014; E6: Sakha 2013/2014.

11 Fig.3. Bi-plot showing a comparison of all genotypes with the ideal genotype constructed based on 12 environment-centered and genotype focused singular-value partitioning. The $\mathrm{x}$-axis shows the main 13 effects, while the y-axis shows the first PCA axis. See codes of environments and genotypes in table 143.

$15 \quad$ Fig.4.

16 Distribution of the 60 barley genotypes on Alpha-Lambda areas I, II and III indicate regions of 17 average, above and below average stability according to (Tai, 1971) method.

18 Fig.5. Box plots showing the individual scores and the means, the circle 'o' stands for outliers.

19 The upper and lower lines outside the box stand for max and min adjacent value, respectively.

20 The upper and lower hinge of the box stands for $75 \%$ and $25 \%$ percentile, respectively. 
1 Fig.6. Histogram showing the contribution effects of 6-environments for grain yields obtained by

2 a resembling procedure, between the first principal component (eigenvector) of both matrices of 3 co-variance for grain yield. 


\section{REFERENCES}

2 Balestre M, Von Pinho RG, Souza JC, Oliveira RL. 2009. Genotypic stability and adaptability in tropical maize based on AMMI and GGE biplot analysis. Genet. Mol. Res. 8: 1311-1322

4 Ceccarelli S. 1996. Positive interpretation of genotype by environment interactions in relation to 5 sustainability and biodiversity. In: M. Cooper, GL Hammer (eds) Plant adaptation and crop

Demissew A, Hussein S, Derera J. 2016. Genotype-by-environment interaction and yield stability of quality protein maize hybrids developed from tropicalhighland adapted inbred lines. Euphytica 209: 757-769

Elakhdar A, Abd El-Sattar M, Amer K, Kumamaru T. 2016a. Genetic diversity and association analysis among Egyptian barley (Hordeum vulgare L.) genotypes with different adaptations to saline conditions analyzed by SSR markers. AJCS 10: 637-645

Elakhdar A, Abdelsattar ., Amer K, Assma R, T. Kumamaru. 2016b. Population structure and marker-trait association of salt tolerance in barley (Hordeum vulgare L.). C. R. Biologies 339: $454-461$

FAO. 2015. Land and plant nutrition management service. Available at http://www.fao.org/.

Finlay K, Wilkinson G. 1963. The analysis of adaptation in a plant-breeding programme. Aust. J. Agric. Res. 14: 742-754 
1 Garcia del Moral L, Miralles, DJ Slafer GA. 2002. Barley Physiology: Phasic and foliar 2 development In. "Barley science: recent advances from molecular biology to agronomy of 3 yield and quality" (Eds. Slafer GA, Molina-Cano JL, Savin R, Araus, JL Romagosa I). 4 Food Product Press (New York, USA), an imprint of The Haworth Press, Inc., New York, 521 capítulos, c. 664 pp. ISBN 1-56022-909-8, (243-268)

6 Gauch HG. 1992 Statistical analysis of regional yield trials: AMMI analysis of factorial designs.

$7 \quad$ Elsevier, Amsterdam

8 Gauch HG Jr 2006 Statistical analysis of yield trials by AMMI and GGE. Crop Sci 46:1488$9 \quad 1500$

10 Gauch HG, Piepho HP, Annicchiarico P. 2008. Statistical analysis of yield trials by AMMI and 11 GGE: Further considerations. Crop Sci. 48: 866-889

12 Gauch HG, Zobel RW. 1997. Identifying Mega-Environments and Targeting Genotypes. Crop $13 \quad$ Sci. $37: 311$

14 GenStat. 2011. GenStat for Windows 14th Edition. VSN International, Hemel Hempstead, UK. 15 Web page: GenStat.co.uk.

16 Haussmann, BI, Parzies HK, Presterl T, Suši Z, Miedaner T. 2004. Plant genetic resources in 17 crop improvement. Plant Genet. Resour. 2: 3-21.

18 Hongyu K, García-Peña M, De Araújo LB, Dos Santos Dias CT. 2014. Statistical analysis of 19 yield trials by AMMI analysis of genotype $\times$ environment interaction. Biometrical Lett. 51: $20 \quad 89-102$

21 Kang MS, Gauch HG. (eds). 1996. Genotype-by-Environment Interaction. CRC Press, Boca 22 Raton, Florida. Kang.

23 Kole C, Muthamilarasan M, Henry R, Edwards D, Sharma R. 2015. Application of genomics- 
assisted breeding for generation of climate resilient crops: progress and prospects. Front. Plant Sci. 6: 563

3 Laemmli, UK. 1970. Cleavage of Structural Proteins during the Assembly of the Head of $4 \quad$ Bacteriophage T4. Nature 227: 680-685

5 Liu, WJ, Li HJ, Wang XD, Zhou KD. 2002. Stability analysis for elementary characters of 6 hybrid rice by AMMI model. Acta Agron. Sin. 28: 569-573

7 Lobell DB, Schlenker W, Costa-Roberts J. 2011. Climate trends and global crop production 8 since 1980. Science 333: 616-20

9 Malosetti M, Ribaut JM, van Eeuwijk FA. 2013. The statistical analysis of multi-environment 10 data: Modeling genotype-by-environment interaction and its genetic basis. Front. Physiol. $11 \quad 4: 44$

12 Munns R. 1993. Physiological processes limiting plant growth in saline soils: some dogmas and 13 hypotheses. Plant Cell Environ. 16: 15-24

14 Munns R, Tester M. 2008. Mechanisms of Salinity Tolerance. Annu. Rev. Plant Biol. 59: 65115

16 Nei, M., 1978. Estimation of average heterozygosity and genetic distance from a small number 17 of individuals. Genetics 89: $583-590$

18 Nurminiemi M, Madsen S, Rognli OA, Bjørnstad Ã, Ortiz R. 2002. Analysis of the genotype19 by-environment interaction of spring barley tested in the Nordic Region of Europe: 20 Relationships among stability statistics for grain yield. Euphytica 127: 123-132

21 Reza M, Ezatollah F, A Ahmed. 2015. Interpreting genotype $\times$ environment interactions for

\section{2 grain yield of rainfed durum wheat in Iran. Crop J. 3: 526-535}

23 Rharrabti Y, García Del Moral LF, Villegas D, Royo C. 2003. Durum wheat quality in 
Mediterranean environments III. Stability and comparative methods in analysing G Â E interaction. F. Crop. Res. 80: 141-146

Rodriguez M, Rau D, Papa R, AtteneG. 2008. Genotype by environment interactions in barley (Hordeum vulgare L.): different responses of landraces, recombinant inbred lines and varieties to Mediterranean environment. Euphytica 163: 231-247

Sayar R, Bchini H, Mosbahi, Khemira H. 2010. Response of durum wheat (Triticum durum Desf.) growth to salt and drought stresses. Czech J. Genet. Plant Breed. - UZEI (Czech Republic).

Shafii B, Price WJ. 1998. Analysis of Genotype-by-Environment Interaction Using the Additive Main Effects and Multiplicative Interaction Model and Stability Estimates. J. Agric. Biol. Environ. Stat. 3: 335

Smith JB, Tirpak, DA eds. 1989. The Potential Effects of Global Climate Change on the United States. Report to Congress. EPA-230-05-89-050. Washington, DC: US Environmental Protection Agency

Tai, G. 1971. Genotypic Stability Analysis and Its Application to Potato Regional Trials. Crop Sci. 11: 184

Temesgen T, Keneni G, Sefera T, Jarso M. 2015. Yield stability and relationships among stability parameters in faba bean (Vicia faba L.) genotypes. Crop J. 3: 258-268

Thillainathan M, Fernandez GC. 2001. SAS applications for Tai's stability analysis and AMMI model in genotype $\mathrm{x}$ environmental interaction (GEI) effects. J. Hered. 92: 367-71

Yahiaoui S, Cuesta-Marcos A, Gracia MP, Medina B, Lasa JM, Casas AM, Ciudad FJ, Montoya JL, Moralejo M, Molina-Cano JL, Igartua E. 2014. Spanish barley landraces outperform modern cultivars at low-productivity sites. Plant Breed. 133: 218-226 
1 Yan W, Kang MS. 2003. GGE biplot analysis: a graphical tool for breeders, geneticists, and 2 agronomists. CRC Press

3 Yan W, Kang MS, Ma B, S. Woods, and P.L. Cornelius. 2007. GGE Biplot vs. AMMI Analysis

4 of Genotype-by-Environment Data. Crop Sci. 47: 643 -653

5 Yang RC, Crossa J, Cornelius PL, J Burgueño. 2009. Biplot analysis of genotype $\times$ environment 6 interaction: Proceed with caution. Crop Sci. 49: 1564-1576

7 Zobel RW, Wright MJ, Gauch HG. 1988. Statistical Analysis of a Yield Trial. Agron. J. 80: 388 $8 \quad-393$ 
Table 1. Description of the testing location during the two seasons

\begin{tabular}{|c|c|c|c|c|c|c|c|c|c|}
\hline locations & Annual & Nov & Dec & Jan & Feb & Mar & Apr & May & Jun \\
\hline \multicolumn{10}{|l|}{ Average temperature/ $\mathrm{C}$} \\
\hline 1 & 20.1 & 18.4 & 14.7 & 13.0 & 13.6 & 15.4 & 19.0 & 22.2 & 25.2 \\
\hline 2 & 19.2 & 15.4 & 20.2 & 13.5 & 14.0 & 15.7 & 18.6 & 21.6 & 24.7 \\
\hline 3 & 21.0 & 20.0 & 16.0 & 14.0 & 14.0 & 16.0 & 19.0 & 21.0 & 25.0 \\
\hline \multicolumn{10}{|l|}{ Average precipitation $/ \mathrm{mm}$} \\
\hline 1 & 71.0 & 8.4 & 14.3 & 19.5 & 12.6 & 6.3 & 4.8 & 2.0 & --- \\
\hline 2 & 13.9 & 21.9 & 117.6 & 28.6 & 18.1 & 17.4 & 6.2 & 1.4 & 0.3 \\
\hline 3 & 40.0 & --- & --- & --- & --- & --- & --- & --- & --- \\
\hline \multicolumn{10}{|c|}{ Average number of days with precipitation/ days } \\
\hline 1 & 32.0 & 3.5 & 6.1 & 7.9 & 5.8 & 4.1 & 1.7 & 0.6 & 0.1 \\
\hline 2 & 4.7 & 6.9 & 37.5 & 8.9 & 6.6 & 4.6 & 2.1 & 0.8 & 0.2 \\
\hline 3 & & --- & --- & --- & --- & --- & --- & --- & --- \\
\hline \multicolumn{10}{|l|}{ Average length of day/ 12.6} \\
\hline 1 & 10.8 & 10.6 & & 11.5 & 12.4 & 12.4 & 14.2 & 14.6 & 14.4 \\
\hline 2 & 11.0 & 10.6 & 12.6 & 10.8 & 11.5 & 12.4 & 12.4 & 14.2 & 14.6 \\
\hline 3 & & --- & --- & --- & --- & --- & --- & --- & --- \\
\hline \multicolumn{10}{|l|}{ Average relative humidity/ \% } \\
\hline 1 & 68.4 & 72.0 & 71.8 & 71.6 & 70.4 & 68.2 & 62.6 & 61.0 & 62.7 \\
\hline 2 & 73.1 & 73.4 & 71.2 & 73.2 & 72.1 & 70.7 & 67.5 & 67.5 & 68.0 \\
\hline 3 & & & & & & & & & \\
\hline \multicolumn{10}{|l|}{ Average dew point/ $\mathrm{C}$} \\
\hline 1 & 14.1 & 13.3 & 9.7 & 8.0 & 8.3 & 9.6 & 11.7 & 14.3 & 17.6 \\
\hline 2 & 14.3 & 10.7 & 14.8 & 8.8 & 9.1 & 10.4 & 12.5 & 15.3 & 18.4 \\
\hline 3 & 15.0 & 14.0 & 11.0 & 8.0 & 8.0 & 10.0 & 13.0 & 15.0 & 18.0 \\
\hline \multicolumn{10}{|l|}{ Average wind speed $/ \mathrm{km} / \mathrm{h}$} \\
\hline 1 & 10.7 & 9.4 & 10.1 & 10.8 & 11.9 & 12.6 & 12.2 & 11.9 & 10.8 \\
\hline 2 & 11.5 & 11.9 & 12.9 & 12.6 & 14.0 & 15.5 & 14.8 & 14.0 & 13.3 \\
\hline 3 & 22.0 & 25.0 & 30.0 & 19.0 & 25.0 & 20.0 & 22.0 & 20.0 & 19.0 \\
\hline
\end{tabular}

Loc-1: Sakha, Kafrelsheikh prefecture (Elevation: 9 meters -Latitude: 31 07N -Longitude: 030 56E); Loc-2: Seirw , Damietta prefecture (Elevation: 12 meters- Latitude: 31 25N - Longitude: 031 49E) and Loc-3: Elhossinia, Isma'iliyah prefecture (Elevation: 13 meters-Latitude: 30 36N-Longitude: 032 $15 \mathrm{E})$.

Source: World weather \& climate information (https://weather-and-climate.com/) 
Table 2. The soil properties; chemical, physical, and textural characterize for the testing location.

\section{Soil properties}

\begin{tabular}{|c|c|c|c|c|c|c|c|c|c|c|c|c|c|c|c|c|c|c|c|c|c|}
\hline Location & 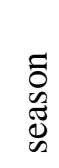 & I & $\begin{array}{l}\qquad \\
0 \\
0 \\
0 \\
0\end{array}$ & $\begin{array}{l}0 \\
0 \\
0 \\
0 \\
0\end{array}$ & $\begin{array}{l}\therefore 0 \\
\hat{n}\end{array}$ & $\begin{array}{l}0 \\
\frac{1}{4} \\
\text { a }\end{array}$ & $\frac{\vec{d}}{\mathrm{~d}}$ & U & $\sum^{+}{ }^{+}$ & $\begin{array}{l}\ddagger \\
\tilde{z} \\
z\end{array}$ & $\stackrel{+}{ \pm}$ & $\frac{\sigma^{2}}{5}$ & Õ & $\bar{U}$ & $\underset{\overbrace{}}{0}$ & é & & 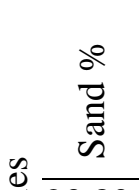 & $\begin{array}{l}\stackrel{0}{0} \\
\overline{5}\end{array}$ & $\begin{array}{l}\stackrel{0}{2} \\
\stackrel{\Xi}{U}\end{array}$ & 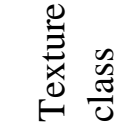 \\
\hline \multirow[t]{2}{*}{$\overline{\mathrm{LOC}-1}$} & & 7.83 & 10.90 & 3.95 & 2.90 & 8.90 & & 20.70 & 40.30 & 47.05 & 0.95 & \multirow{6}{*}{ 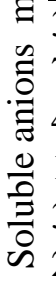 } & 38.87 & 67.00 & 3.13 & \multirow{2}{*}{$\begin{array}{ll}3 & - \\
0 & -\end{array}$} & \multirow{6}{*}{\multicolumn{5}{|c|}{ 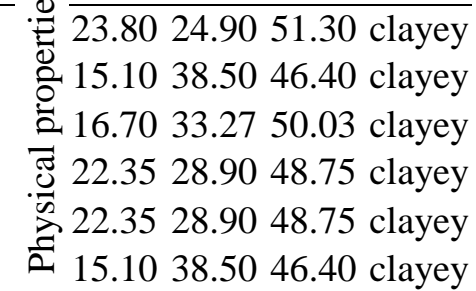 }} \\
\hline & & & 9.50 & 2.32 & ) & 8.40 & & 51.00 & 30.60 & 53.50 & 0.40 & & 72.50 & 60.00 & 3.00 & & & & & & \\
\hline LOC-2 & 1 & 7.97 & 10.50 & 10.50 & 51.35 & 16.20 & ]్ & 28.98 & 48.75 & 46.37 & 0.90 & & 44.20 & 58.00 & 2.81 & - & & & & & \\
\hline & $2^{\mathrm{n}}$ & 8.12 & 11.55 & 2.18 & 50.20 & 15.20 & $\frac{0}{2}$ & 57.80 & 38.20 & 105.10 & 0.85 & & 108.40 & 90.00 & 4.00 & - & & & & & \\
\hline OCC-3 & -1 s & & 6.80 & 6.80 & 52.30 & 18 & 咅 & 6.90 & 16.90 & 44.30 & 0.80 & & 31.77 & 44.00 & 3.13 & - & & & & & \\
\hline & & .75 & 22.44 & 2.55 & 51.50 & 17.45 & & 176.80 & 130.40 & 216.10 & 2.10 & & 241.90 & 280.00 & 3.50 & . & & & & & \\
\hline
\end{tabular}

Loc-1: Sakha, Kafrelsheikh prefecture; Loc-2: Seirw , Damietta prefecture Loc-3: Elhossinia, Isma'iliyah prefecture. (Elakhdar et al. 2016b). 
Table 3. The performance of grain yield $\left(\right.$ tha $\left.^{-1}\right)$ for 60 barley genotypes tested in six environments.

\begin{tabular}{|c|c|c|c|c|c|c|c|c|c|c|c|c|c|}
\hline \multirow[b]{2}{*}{ Genotype } & \multicolumn{6}{|l|}{ Set-1 } & \multicolumn{7}{|c|}{ Set-2 } \\
\hline & E1 & E2 & E3 & $\mathrm{E} 4$ & E5 & E6 & Genotype & E1 & E2 & E3 & $\mathrm{E} 4$ & E5 & E6 \\
\hline G-1 & 2.29 & 1.56 & 2.13 & 3.58 & 2.29 & 2.19 & G-16 & 2.40 & 01.48 & 2.65 & 1.88 & 1.98 & 3.23 \\
\hline G-2 & 2.04 & 1.04 & 2.33 & 2.71 & 3.06 & 2.50 & G-17 & 2.19 & 91.27 & 1.88 & 1.25 & 2.81 & 1.77 \\
\hline G-3 & 2.33 & 1.56 & 2.73 & 2.71 & 2.71 & 2.60 & G-18 & 1.73 & 31.67 & 3.33 & 2.29 & 3.33 & 3.33 \\
\hline-4 & 2.19 & 1.67 & 2.08 & 2.29 & 2.50 & 3.54 & G-19 & 1.58 & 81.04 & 2.60 & 1.67 & 2.29 & 1.56 \\
\hline-5 & 1.60 & 1.77 & 2.40 & 1.40 & 2.08 & 1.51 & G-20 & 1.71 & 11.35 & 1.88 & 2.08 & 2.92 & 2.19 \\
\hline G-6 & 2.29 & 1.10 & 2.71 & 1.56 & 3.06 & 2.08 & G-21 & 2.29 & 91.56 & 1.04 & 2.81 & 2.19 & 2.19 \\
\hline G-7 & 2.23 & 1.25 & 2.08 & 1.92 & 2.29 & 2.67 & G-22 & 2.40 & 01.42 & 2.60 & 2.92 & 2.71 & 3.13 \\
\hline G-8 & 2.08 & 1.04 & 2.50 & 3.13 & 3.02 & 3.33 & G-23 & 1.63 & 31.21 & 2.02 & 2.71 & 2.92 & 2.19 \\
\hline G-9 & 1.48 & 1.25 & 2.04 & 1.54 & 3.65 & 2.92 & G-24 & 2.31 & 10.83 & 2.08 & 2.04 & 2.19 & 2.34 \\
\hline G-10 & 2.08 & 1.09 & 2.08 & 1.77 & 2.60 & 2.29 & G-25 & 2.19 & 91.46 & 2.04 & 2.77 & 2.40 & 2.15 \\
\hline G-11 & 1.90 & 1.35 & 2.35 & 2.81 & 2.71 & 2.92 & G-26 & 1.27 & 71.00 & 1.81 & 1.35 & 3.02 & 1.98 \\
\hline G-12 & 1.63 & 1.10 & 1.88 & 1.88 & 2.19 & 3.13 & G-27 & 1.98 & 81.35 & 2.81 & 3.02 & 2.60 & 1.77 \\
\hline G-13 & 1.35 & 0.73 & 2.08 & 1.71 & 2.50 & 2.40 & G-28 & 1.83 & 31.94 & 2.92 & 2.92 & 1.98 & 2.50 \\
\hline G-14 & 1.04 & 1.15 & 2.02 & 1.81 & 2.50 & 2.40 & G-29 & 2.40 & 01.77 & 1.83 & 3.23 & 3.33 & 2.50 \\
\hline G-15 & 2.04 & 1.46 & 2.71 & 1.77 & 2.44 & 2.81 & G-30 & 2.81 & 12.19 & 2.02 & 3.17 & 2.60 & 3.17 \\
\hline
\end{tabular}

E1: Elhossinia 2012/2013; E2: Seirw 2012/2013; E3: Sakha 2012/2013; E4: Elhossinia 2013/2014; E5: Seirw 2013/2014; E6: Sakha 2013/2014. 
Cont table 3.

\begin{tabular}{|c|c|c|c|c|c|c|c|c|c|c|c|c|c|}
\hline \multirow[b]{2}{*}{ Genotype } & \multicolumn{8}{|l|}{ Set-3 } & \multicolumn{5}{|c|}{ Set-4 } \\
\hline & $\mathrm{E} 1$ & E2 & E3 & E4 & E5 & E6 & Genotype & E1 & E2 & E3 & E4 & E5 & E6 \\
\hline G-31 & 1.15 & 1.04 & 2.04 & 1.10 & 2.40 & 1.98 & G-46 & 1.21 & 1.04 & 2.81 & 2.19 & 1.17 & 2.81 \\
\hline G-32 & 1.69 & 1.85 & 3.33 & 1.38 & 3.44 & 2.50 & G-47 & 1.48 & 1.85 & 2.60 & 1.48 & 1.88 & 2.71 \\
\hline G-33 & 1.83 & 2.19 & 2.69 & 2.15 & 3.19 & 1.98 & G-48 & 1.42 & 2.19 & 1.83 & 1.63 & 2.33 & 2.00 \\
\hline G-34 & 1.88 & 1.88 & 2.98 & 1.71 & 3.33 & 1.88 & G-49 & 1.56 & 1.88 & 1.98 & 1.58 & 2.10 & 2.06 \\
\hline G-35 & 1.17 & 1.98 & 2.54 & 0.83 & 3.75 & 1.77 & G-50 & 1.58 & 1.98 & 1.88 & 1.63 & 2.25 & 1.23 \\
\hline G-36 & 1.90 & 1.44 & 3.02 & 1.63 & 3.02 & 1.88 & G-51 & 2.13 & 1.44 & 2.29 & 2.23 & 1.69 & 2.02 \\
\hline G-37 & 1.83 & 1.77 & 1.98 & 2.00 & 3.44 & 2.08 & G-52 & 1.17 & 1.77 & 2.08 & 1.21 & 1.83 & 2.21 \\
\hline G-38 & 1.52 & 1.46 & 2.50 & 2.15 & 2.92 & 2.08 & G-53 & 1.54 & 1.46 & 1.56 & 1.54 & 1.46 & 1.42 \\
\hline G-39 & 1.77 & 1.44 & 2.40 & 1.56 & 3.23 & 1.77 & G-54 & 1.44 & 1.44 & 2.08 & 1.44 & 1.42 & 1.94 \\
\hline $\mathrm{G}-40$ & 1.48 & 1.05 & 1.60 & 1.50 & 2.40 & 1.46 & G-55 & 1.25 & 1.05 & 1.38 & 1.25 & 1.13 & 1.00 \\
\hline G-41 & 1.46 & 1.42 & 1.98 & 0.83 & 3.44 & 1.46 & G-56 & 1.88 & 1.42 & 1.98 & 1.88 & 1.94 & 1.63 \\
\hline G-42 & 2.50 & 1.50 & 1.81 & 1.83 & 3.23 & 1.98 & G-57 & 1.58 & 1.50 & 1.88 & 1.79 & 1.75 & 1.96 \\
\hline G-43 & 1.88 & 1.98 & 1.81 & 1.38 & $\underline{4.00}$ & 2.29 & G-58 & 1.56 & 1.98 & 1.88 & 1.65 & 2.56 & 1.73 \\
\hline G-44 & 1.33 & $\underline{0.63}$ & 2.08 & 1.54 & 3.02 & 1.23 & G-59 & 1.38 & $\underline{0.63}$ & 2.23 & 1.56 & 0.73 & 2.21 \\
\hline G-45 & 1.71 & 1.88 & 2.81 & 1.71 & 2.81 & 1.46 & G-60 & 1.58 & 1.88 & 1.98 & 1.67 & 1.94 & 2.21 \\
\hline
\end{tabular}

E1: Elhossinia 2012/2013; E2: Seirw 2012/2013; E3: Sakha 2012/2013; E4: Elhossinia 2013/2014; E5:

Seirw 2013/2014; E6: Sakha 2013/2014. 
Table 4. AMMI adjusted mean grain yield $\left(\mathrm{t} \mathrm{ha}^{-1}\right)$, and IPCA scores of genotypes of 60 spring barley evaluated across sixenvironments in Egypt.

\begin{tabular}{|c|c|c|c|c|c|c|c|c|c|c|c|}
\hline \multirow{2}{*}{$\frac{\text { Set-1 }}{\text { Genotype }}$} & \multicolumn{11}{|c|}{ Set-2 } \\
\hline & $\mathrm{Gm}$ & IPCA1 & IPCA2 & $\alpha$ & $\lambda$ & Genoty & $\mathrm{Gm}$ & IPCA1 & IPCA2 & $\alpha$ & $\lambda$ \\
\hline G-1 & 2.34 & -0.96 & -0.38 & -0.38 & 3.79 & G-16 & 2.37 & -0.14 & 0.19 & -0.37 & 2.72 \\
\hline G-2 & 2.28 & -0.21 & 0.02 & $\underline{0.23}$ & $\underline{0.96}$ & G-17 & 2.04 & 0.20 & 0.21 & -0.25 & 2.14 \\
\hline G-3 & $\underline{2.44}$ & -0.20 & -0.27 & -0.09 & 2.18 & G-18 & 2.13 & -0.90 & 0.02 & 0.50 & 2.60 \\
\hline G-4 & $\underline{2.38}$ & $\underline{-0.07}$ & 0.39 & 0.74 & 1.46 & G-19 & 2.21 & -0.18 & 0.56 & -0.10 & 1.54 \\
\hline G-5 & $\underline{1.79}$ & 0.30 & -0.82 & -0.58 & 0.47 & G-20 & 2.04 & $\underline{0.05}$ & -0.82 & 0.14 & 0.51 \\
\hline G-6 & 2.14 & 0.49 & -0.42 & -0.23 & 4.42 & G-21 & 1.93 & 0.71 & 0.27 & -0.42 & 2.76 \\
\hline G-7 & 2.07 & $\underline{0.00}$ & -0.05 & -0.18 & 0.75 & G-22 & $\underline{2.51}$ & $\underline{-0.02}$ & 0.25 & 0.35 & 0.51 \\
\hline G-8 & $\underline{2.52}$ & -0.39 & 0.45 & 0.74 & 2.08 & G-23 & 2.09 & $\underline{-0.01}$ & -0.44 & 0.48 & 0.48 \\
\hline G-9 & 2.15 & 0.66 & 0.46 & 1.05 & 1.52 & G-24 & 2.17 & 0.12 & 0.28 & 0.17 & 0.81 \\
\hline G-10 & 1.99 & 0.15 & -0.15 & -0.21 & 0.32 & G-25 & 2.23 & 0.23 & -0.02 & -0.16 & 0.38 \\
\hline G-11 & 2.34 & -0.31 & 0.16 & 0.60 & 1.81 & G-26 & $\underline{1.76}$ & $\underline{0.00}$ & 0.27 & 0.37 & 1.88 \\
\hline G-12 & 1.97 & $\underline{-0.01}$ & 0.42 & 0.10 & 1.57 & G-27 & 2.19 & -0.44 & -0.18 & 0.13 & 1.85 \\
\hline G-13 & 1.80 & 0.15 & 0.15 & -0.52 & 1.44 & G-28 & $\underline{2.44}$ & -0.42 & -0.11 & -0.59 & 1.80 \\
\hline G-14 & 1.82 & 0.13 & 0.14 & -0.51 & 0.55 & G-29 & 2.24 & 0.36 & -0.19 & 0.24 & 1.62 \\
\hline G-15 & 2.21 & 0.27 & -0.12 & -0.74 & 1.39 & G-30 & $\underline{2.47}$ & 0.45 & -0.29 & -0.48 & 1.20 \\
\hline
\end{tabular}

E1: Elhossinia 2012/2013; E2: Seirw 2012/2013; E3: Sakha 2012/2013; E4: Elhossinia 2013/2014; E5: Seirw 2013/2014; E6: Sakha 2013/2014. Deviations are in units of $\left(\mathrm{t} \mathrm{ha}^{-1}\right)$, IPCA scores are in units of $\left(\mathrm{t} \mathrm{ha}^{-1}\right), \alpha, \lambda$, Tai's alpha and lambda mean-variance component for a pair-wise G×E interaction. 
Table 4. Cont.

\begin{tabular}{|c|c|c|c|c|c|c|c|c|c|c|c|}
\hline \multicolumn{6}{|l|}{ Set-3 } & \multicolumn{6}{|l|}{ Set-4 } \\
\hline Genotype & $\mathrm{Gm}$ & IPCA1 & IPCA2 & $\alpha$ & $\lambda$ & Genotype & $\mathrm{Gm}$ & IPCA1 & IPCA2 & $\alpha$ & $\lambda$ \\
\hline G-31 & 1.62 & $\underline{0.09}$ & -0.16 & $\underline{-0.18}$ & $\underline{0.97}$ & G-46 & 1.87 & -0.92 & 0.11 & 0.95 & 2.70 \\
\hline G-32 & $\underline{2.37}$ & -0.41 & -0.46 & 0.23 & 1.90 & G-47 & $\underline{2.00}$ & -0.25 & 0.54 & 0.96 & 0.64 \\
\hline G-33 & $\underline{2.34}$ & 0.16 & -0.14 & -0.26 & 0.44 & G-48 & 1.90 & 0.43 & 0.32 & -0.68 & 1.96 \\
\hline G-34 & 2.27 & $\underline{-0.09}$ & -0.28 & 0.04 & 0.49 & G-49 & 1.86 & 0.20 & 0.19 & -0.25 & 0.54 \\
\hline G-35 & 2.01 & -0.83 & 0.00 & 0.53 & 1.85 & G-50 & 1.76 & 0.58 & -0.14 & $\underline{-0.95}$ & 2.02 \\
\hline G-36 & 2.15 & $\underline{0.08}$ & -0.42 & $\underline{0.00}$ & $\underline{1.10}$ & G-51 & 1.97 & -0.19 & -0.52 & -0.39 & 1.66 \\
\hline G-37 & 2.18 & 0.18 & 0.39 & $\underline{-0.12}$ & $\underline{0.94}$ & G-52 & 1.71 & 0.02 & 0.53 & 0.82 & 1.11 \\
\hline G-38 & 2.10 & 0.37 & -0.19 & $\underline{-0.23}$ & $\underline{0.95}$ & G-53 & 1.50 & 0.17 & -0.29 & $\underline{-0.95}$ & 0.30 \\
\hline G-39 & 2.03 & $\underline{0.03}$ & 0.01 & 0.05 & 0.07 & G-54 & 1.63 & -0.15 & 0.05 & 0.41 & 0.23 \\
\hline G-40 & $\underline{1.58}$ & 0.45 & 0.14 & -0.37 & 0.40 & G-55 & $\underline{1.17}$ & 0.16 & -0.37 & -0.91 & 0.18 \\
\hline G-41 & 1.76 & -0.43 & 0.27 & 0.36 & 0.67 & G-56 & 1.79 & 0.14 & -0.41 & -0.82 & 0.74 \\
\hline G-42 & 2.14 & 0.42 & 0.54 & -0.27 & 2.19 & G-57 & 1.72 & $\underline{-0.04}$ & -0.13 & -0.30 & 0.17 \\
\hline G-43 & 2.22 & -0.37 & 0.72 & 0.24 & 2.74 & G-58 & 1.89 & 0.53 & 0.11 & -0.91 & 2.23 \\
\hline G-44 & 1.64 & 0.23 & -0.02 & $\underline{0.20}$ & $\underline{1.22}$ & G-59 & 1.46 & -0.77 & -0.17 & 0.97 & 2.80 \\
\hline G-45 & 2.06 & $\underline{0.10}$ & -0.41 & -0.21 & 1.27 & G-60 & 1.88 & 0.09 & 0.18 & -0.16 & 0.35 \\
\hline
\end{tabular}

E1: Elhossinia 2012/2013; E2: Seirw 2012/2013; E3: Sakha 2012/2013; E4: Elhossinia 2013/2014; E5: Seirw 2013/2014; E6: Sakha 2013/2014.

Deviations are in units of $\left(\mathrm{t} \mathrm{ha}^{-1}\right)$, IPCA scores are in units of $\left(\mathrm{t} \mathrm{ha}^{-1}\right), \alpha, \lambda$, Tai's alpha and lambda mean-variance component for a pair-wise G×E interaction. 
Table 5. The environments mean grain yield $\left(\mathrm{t} \mathrm{ha}^{-1}\right)$, and IPCA scores of 60 spring barley evaluated across six-environments in Egypt.

\begin{tabular}{|c|c|c|c|c|c|c|c|c|c|c|c|c|c|c|c|}
\hline Set-1 & & & & Set-2 & & & & Set-3 & & & & Set-4 & & & \\
\hline Environment & $\mathrm{Em}$ & IPCA1 & IPCA2 & Environment & $\mathrm{Em}$ & IPCA1 & IPCA2 & Environment & $\mathrm{Em}$ & IPCA1 & IPCA2 & Environment & $\mathrm{Em}$ & IPCA1 & IPCA2 \\
\hline E1 & 1.91 & -0.08 & -0.44 & E1 & 2.05 & 0.60 & 0.07 & E1 & 1.67 & 0.46 & 0.36 & E1 & $\underline{1.52}$ & 0.10 & -0.71 \\
\hline $\mathrm{E} 2$ & $\underline{1.28}$ & 0.20 & -0.48 & $\mathrm{E} 2$ & $\underline{1.44}$ & 0.13 & -0.35 & $\mathrm{E} 2$ & 1.57 & -0.39 & 0.07 & $\mathrm{E} 2$ & 1.57 & 0.73 & 0.38 \\
\hline E3 & 2.28 & 0.36 & -0.49 & E3 & 2.24 & -1.26 & 0.15 & E3 & 2.37 & -0.28 & -1.13 & E3 & $\underline{2.03}$ & -0.65 & 0.12 \\
\hline E4 & 2.17 & -1.24 & 0.06 & E4 & 2.40 & 0.16 & -0.92 & E4 & $\underline{1.55}$ & 0.96 & -0.03 & E4 & 1.65 & -0.26 & -0.64 \\
\hline E5 & $\underline{2.64}$ & 0.65 & 0.28 & E5 & $\underline{2.63}$ & 0.44 & 0.81 & E5 & $\underline{3.17}$ & -0.70 & 0.60 & E5 & 1.74 & 0.89 & 0.24 \\
\hline E6 & 2.62 & 0.12 & 1.08 & E6 & 2.38 & -0.07 & 0.26 & E6 & 1.85 & -0.05 & 0.13 & E6 & 1.94 & -0.81 & 0.61 \\
\hline
\end{tabular}


Table 6. Analysis of variance for grain yield of 60 barley genotypes tested across six salt- affected soil environments.

\begin{tabular}{|c|c|c|c|c|c|c|c|c|c|}
\hline \multirow[b]{2}{*}{ SOV } & \multicolumn{3}{|c|}{ Set-1 } & \multicolumn{2}{|l|}{ Set-2 } & \multirow{2}{*}{$\frac{\text { Set-3 }}{\mathrm{MS}}$} & \multicolumn{3}{|c|}{ Set-4 } \\
\hline & $\overline{\mathrm{df}}$ & MS & $\mathrm{VC} \%$ & MS & $\mathrm{VC} \%$ & & $\mathrm{VC} \%$ & & VC $\%$ \\
\hline Rep. & 12 & $0.40 * *$ & 2.76 & $1.00 * *$ & 6.85 & $0.39 * *$ & 2.56 & $0.21 * *$ & 3.10 \\
\hline Treatments $^{+}$ & 89 & $1.21 * *$ & $61.74^{+}$ & $0.95 * *$ & $48.35^{+}$ & $1.51 * *$ & $73.93^{+}$ & $0.55^{* *}$ & 59.92 \\
\hline Location (E) & 5 & $11.70 * *$ & 33.34 & $7.75 * *$ & 22.16 & $18.24 * *$ & 49.92 & $1.89 * *$ & 11.50 \\
\hline Genotypes (G) & 14 & $1.02 * *$ & 8.13 & $0.77 * *$ & 6.17 & $1.22 * *$ & 9.39 & $0.90 * *$ & 15.40 \\
\hline$(\mathrm{G} \times \mathrm{E})$ & 70 & $0.50 * *$ & 20.27 & $0.50 * *$ & 20.01 & $0.38 * *$ & 14.61 & $0.38 * *$ & 33.00 \\
\hline $\mathrm{PC} 2$ & 16 & $0.68 * *$ & 22.69 & $0.55 * *$ & 23.42 & $0.59 * *$ & 22.18 & $0.42 * *$ & 36.78 \\
\hline Residuals & 36 & $0.30 * *$ & & $0.33 * *$ & & 0.196 & & 0.05 & \\
\hline
\end{tabular}

MS; mean of squares, $\mathrm{d}$ f; degrees of freedom.

* and $*$ * indicate significant $(0.01<\mathrm{P}<0.05)$ or highly significant $(\mathrm{P}<0.01)$, respectively. VC \%; variance component $\%$

+ Treatments (Genotypes + locations + interaction). 
Table 7. Pearson matrix illustrates the correlation between the salt-related traits across six-environments.

\begin{tabular}{|c|c|c|c|c|c|c|c|c|c|c|c|c|c|c|c|}
\hline Traits & HD & Chl & LA & MD & $\mathrm{PH}$ & SL & Ped & NT & NG & BY & GY & GW & GFP & GFR & $\mathrm{HI}$ \\
\hline \multicolumn{16}{|l|}{$\overline{\mathrm{HD}}$} \\
\hline \multicolumn{16}{|c|}{$-0.27 * *$} \\
\hline LA & & $-0.28 * *$ & & & & & & & & & & & & & \\
\hline MD & & $-0.64 * *$ & & & & & & & & & & & & & \\
\hline \multicolumn{16}{|l|}{ PH } \\
\hline \multicolumn{16}{|c|}{ SL } \\
\hline Ped & & & & $-0.37 * *$ & $0.50 * *$ & & & & & & & & & & \\
\hline NT & & $-0.28^{* * *}$ & & $0.38^{* *}$ & $-0.44 * *$ & & $-0.26 * *$ & & & & & & & & \\
\hline NG & & & & & $0.26^{* * *}$ & & & & & & & & & & \\
\hline BY & & & & $0.37 * *$ & & $0.29 * *$ & $-0.28 * *($ & $0.30 * *$ & & & & & & & \\
\hline GY & & $-0.27 * *$ & & $0.36 * * *$ & & & & $0.51 * *$ & & $0.64 * *$ & & & & & \\
\hline GW & & $-0.43 * * 0$ & $43 * *$ & $0.31 * *$ & & & & & $-0.44 * *$ & & $0.47 * *$ & & & & \\
\hline GFP & $-0.27^{* *}$ & $-0.44 * *$ & & $0.56^{* *}$ & $-0.37 * *$ & & $-0.27 * *$ & $0.50 * *$ & & & $0.44 * *$ & $0.43 * *$ & & & \\
\hline GFR & & & & & & & $0.30^{* *}$ & $-0.29 * *$ & $-0.28 * *$ & & & $0.52 * *$ & $-0.50 * *$ & & \\
\hline $\mathrm{HI}$ & $-0.36^{* * *}$ & & & & & & & $0.27 * *$ & & & $0.56^{* *}$ & $0.36^{* * *}$ & & & \\
\hline
\end{tabular}

**; highly significant at the level of $\mathrm{P}<0.001$ and 0.05 .

Days to Heading (DH) and Maturity (DM), Chlorophyll content (Chl as SPAD value), Flag Leaf Area $\mathrm{cm}^{2}$ (LA), Plant Height (PH), Spike Length (SL), Peduncle length (Ped), Number of Tillers/ $\mathrm{m}^{2}(\mathrm{NT})$, Number of Grains/ spike (NG), thousand-Grain weight (GW), Grain Yield GY $t h^{-1}$, Biological Yield BY $t h^{-1}$, Grain Filling Period (GFP), Grain Filling Rate (GFR) and Harvest Index (HI). 


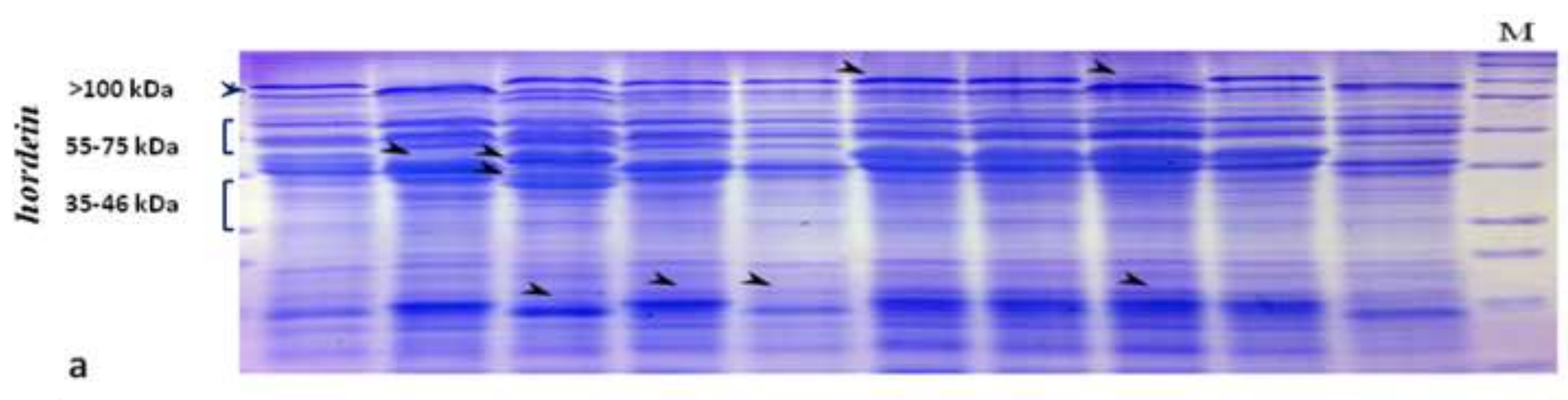

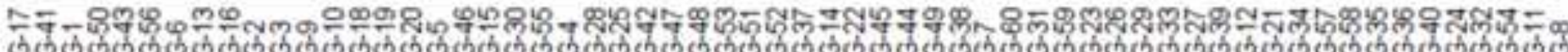

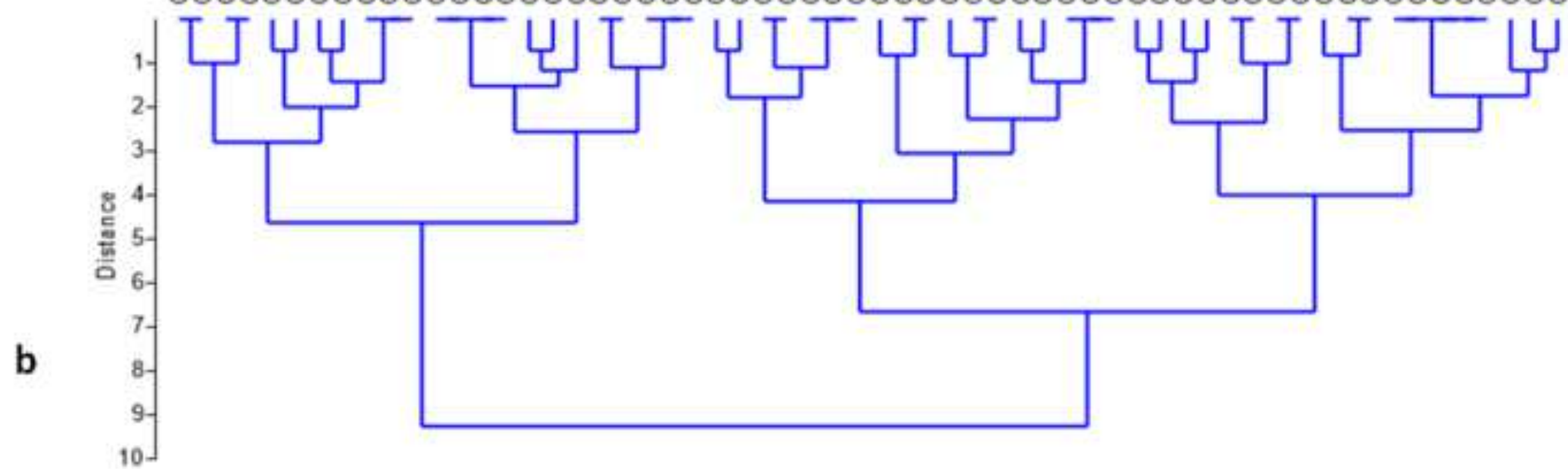



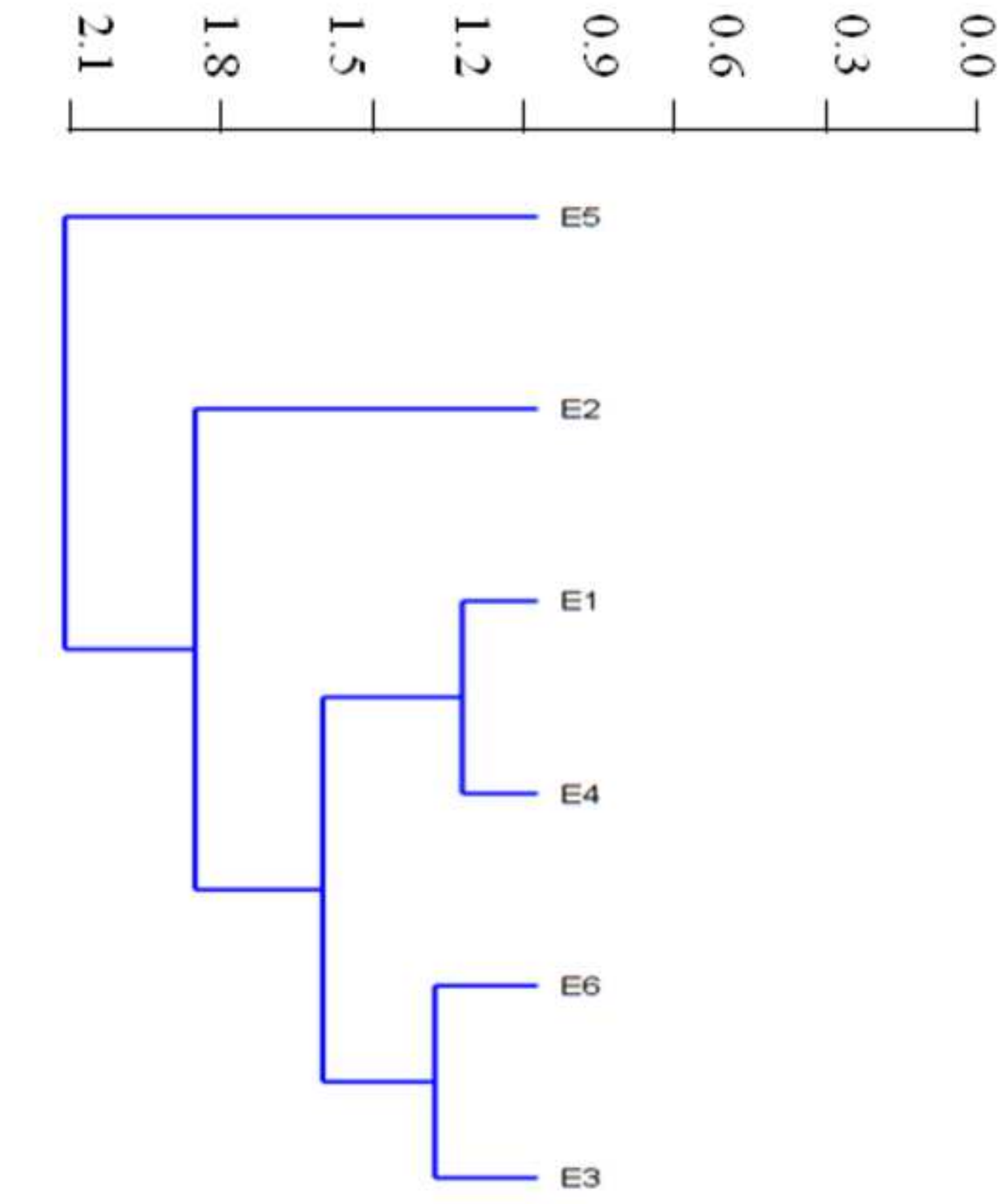

Figure-2

E2

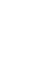



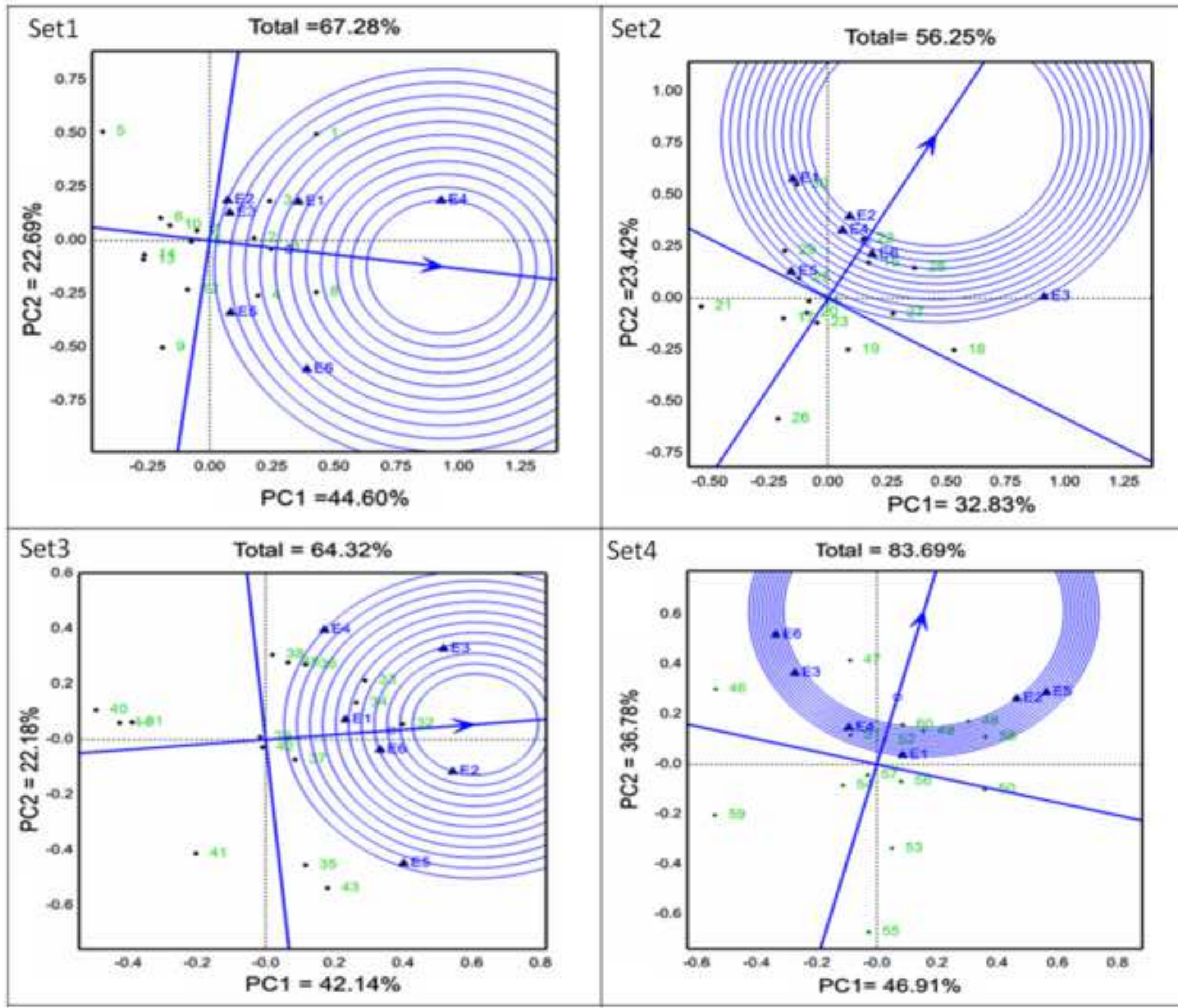


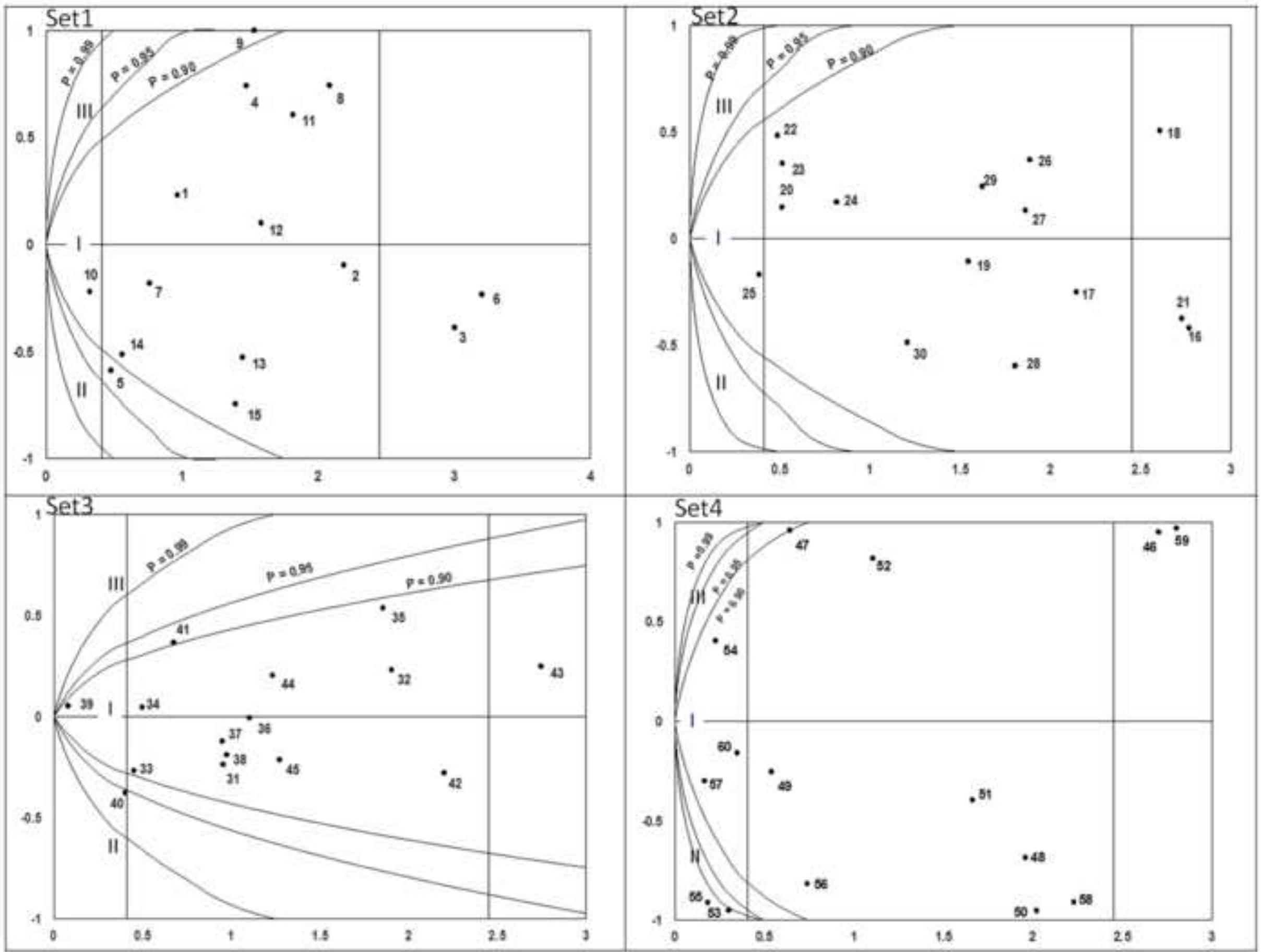




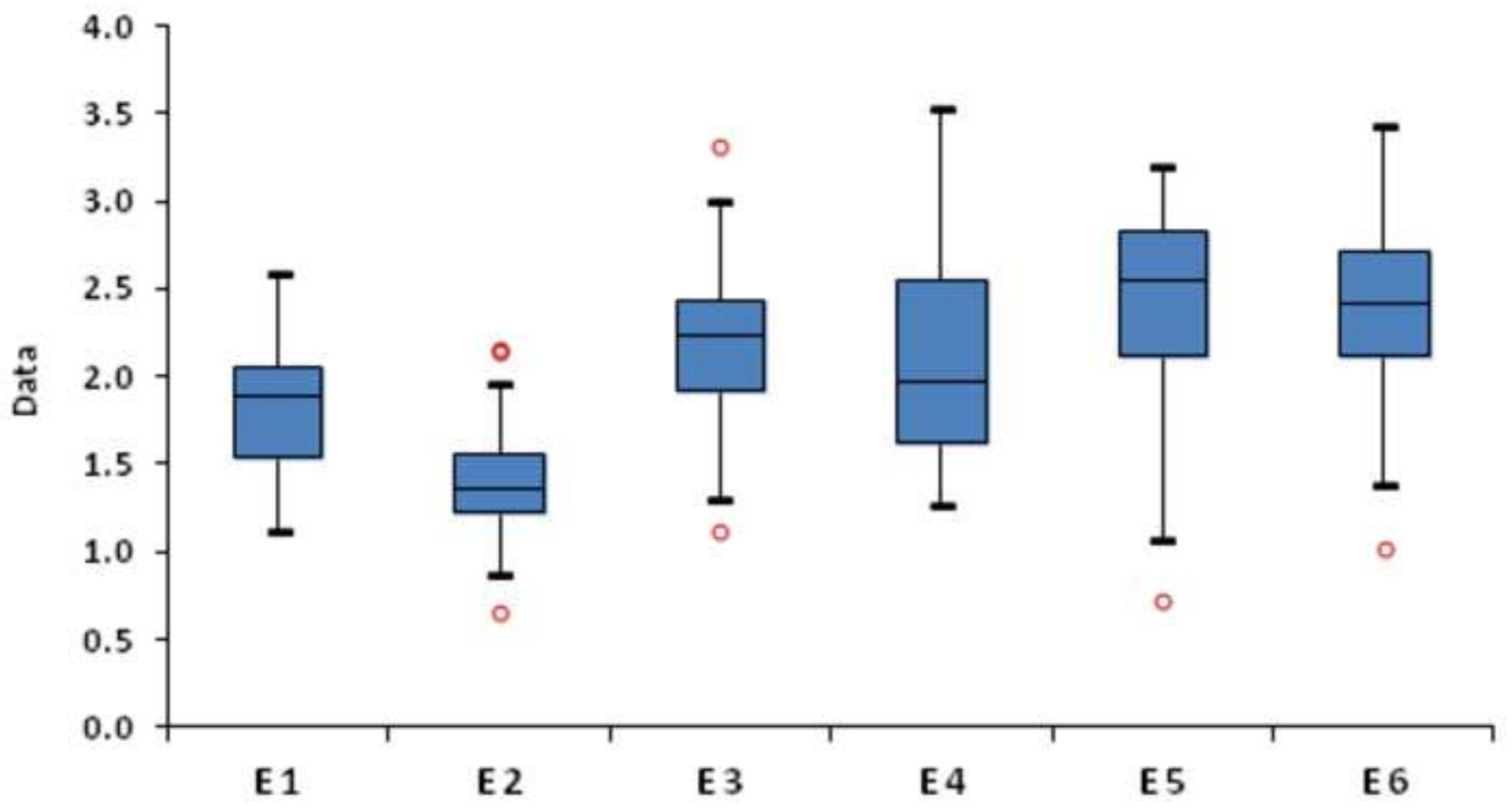

- Lower whisker; - Upper whisker; -Median; o suspected outliers 


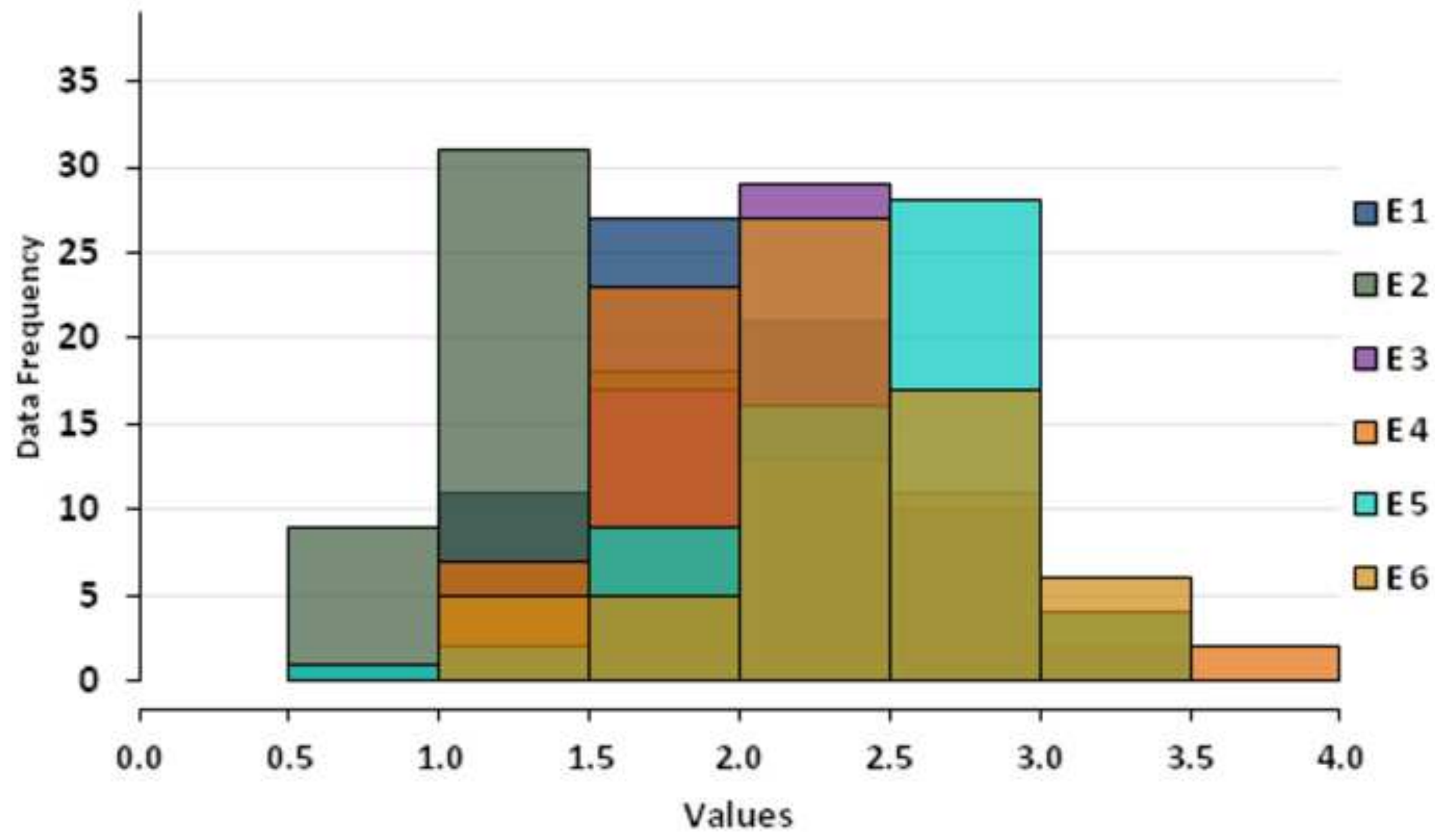



Supplemental Table.xIsx

\section{Click here to access/download Supplementary Material

(n)
Supplemental Table.xlsx 
Click here to access/download Supplementary Material Authors responses.docx 